\title{
Chemoselective Facile Synthesis of the Dicyanophosphide Anion via Electrochemical Activation of White Phosphorus: An Avenue to Or- ganophosphorus Compounds
}

\author{
Yanbo Mei, Zeen Yan, Liu Leo Liu* \\ Department of Chemistry and Shenzhen Grubbs Institute, Southern University of Science and Technology, Shenzhen 518055, \\ China
}

Supporting Information Placeholder

\begin{abstract}
Organophosphorus compounds (OPCs) have gained tremendous interest in the past decades due to their wide applications ranging from synthetic chemistry to materials and biological sciences. We describe herein a practical and versatile approach for the transformation of $\mathrm{P}_{4}$ into useful OPCs with high $\mathrm{P}$ atom economy via a key bridging anion $\left[\mathrm{P}(\mathrm{CN})_{2}\right]^{-}$. This anion can be prepared on a gram scale directly from $\mathrm{P}_{4}$ through an unprecedented electrochemical process. A variety of OPCs involving phosphinidenes, cyclophosphanes and phospholides have been made readily accessible from $\mathrm{P}_{4}$ in a two-step manner. Our approach has a significant impact on the future preparation of OPCs in laboratory and industrial settings.
\end{abstract}

Organophosphorus compounds (OPCs) are widely used as herbicides, flame-retardants, ligands, pharmaceuticals, detergents, and photo-initiators. ${ }^{1}$ Currently, their industrial syntheses demand two phosphorus transfer reagents, namely phosphorus trichloride $\left(\mathrm{PCl}_{3}\right)$ and phosphine gas $\left(\mathrm{PH}_{3}\right) . \mathrm{PCl}_{3}$ is a highly corrosive liquid, which is produced by oxidation of white phosphorus $\left(\mathrm{P}_{4}\right)$ with toxic chlorine gas. The preparation of OPCs via $\mathrm{PCl}_{3}$ involves stepwise displacement of the chloride atoms, and thus inherently has low selectivity and efficiency while concurrently generating chlorine containing waste. ${ }^{2}$ Catalytic transformation of $\mathrm{PH}_{3}$ into OPCs is less preferred as $\mathrm{PH}_{3}$ is an extremely toxic gas and its synthesis from $\mathrm{P}_{4}$ requires harsh reaction conditions. ${ }^{2-3}$ To bypass $\mathrm{PCl}_{3}$ and $\mathrm{PH}_{3}$, tremendous efforts have been devoted into investigating direct functionalization of $\mathrm{P}_{4},{ }^{4}$ whose industrial production is on a scale of more than $10^{6}$ tons per year. However, preparation of OPCs directly from $\mathrm{P}_{4}$ remains extremely challenging; they generally suffer from low selectivity and conversion efficiency or only lead to partial breakup of the $\mathrm{P}_{4}$ tetrahedron. ${ }^{5} \mathrm{~A}$ recent breakthrough by the group of Wolf disclosed that the direct catalytic transformation of $\mathrm{P}_{4}$ into arylphosphines and phosphonium salts via photo-redox catalysis. ${ }^{6}$

Development of phosphorus transfer reagents other than $\mathrm{PCl}_{3}$ and $\mathrm{PH}_{3}$ is a promising strategy for the syntheses of OPCs and other value-added phosphorus-containing chemicals. To this end, Cummins and co-workers demonstrated that the bis(trichlorosilyl)phosphide anion $\left[\mathrm{P}\left(\mathrm{SiCl}_{3}\right)_{2}\right]^{-}(\mathbf{A}$, Figure 1a) derived from phosphates is capable of producing OPCs. ${ }^{7}$ The Grützmacher and Goicoechea groups independently synthesized a large array of unprecedented phosphorus frameworks via the 2-phosphaethynolate anion [OCP] (B, Figure 1a). ${ }^{8}$ More recently, Wolf et. al. reported the synthesis of monophosphines from hydrostannyl phosphines $\left(\mathrm{Bu}_{3} \mathrm{Sn}\right)_{\mathrm{x}} \mathrm{PH}_{3-\mathrm{x}}$ $(\mathrm{x}=1-3)\left(\mathbf{C}\right.$, Figure 1a) resulting from the direct activation of $\mathrm{P}_{4}$ with stannyl radicals. ${ }^{9}$ Although chemical reactions for $\mathrm{P}_{4}$ activation have been explored in depth over the past decades, practical electrochemical activation of $\mathrm{P}_{4}$ is still in its infancy. ${ }^{10}$ The electrocatalytic $\mathrm{C}-\mathrm{P}$ bond formation using transition metal catalysts with sacrificial metal electrodes as reducing reagents have been reported. ${ }^{10}$

(a)

$$
\frac{\left.\mathrm{P}\left(\mathrm{SiCl}_{3}\right)_{2}\right]^{-}}{\text {A }}
$$

$[\mathrm{OCP}]^{-}$

B

$$
\begin{gathered}
\left(\mathrm{Bu}_{3} \mathrm{Sn}\right)_{\mathrm{x}} \mathrm{PH}_{3-\mathrm{x}} \\
\mathbf{C}(\mathrm{x}=1-3)
\end{gathered}
$$

(b)

$$
\begin{array}{ll}
\text { 1) } \mathrm{NaPO}(\mathrm{OEt})_{2} \\
\mathrm{P}(\mathrm{CN})_{3} \underset{-\mathrm{NC}\left[\mathrm{PO}(\mathrm{OEt})_{2}\right]}{\stackrel{2}{\longrightarrow} 18-\mathrm{C}-6} \mathrm{Na}(18-\mathrm{C}-6)\left[\mathrm{P}(\mathrm{CN})_{2}\right]
\end{array}
$$

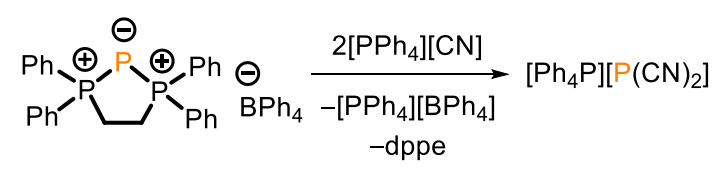

$$
4 \mathrm{P}_{4} \underset{-\mathrm{K}(18-\mathrm{C}-6) \mathrm{P}_{15}}{\stackrel{2 \mathrm{~K}(18-\mathrm{C}-6) \mathrm{CN}}{\longrightarrow}} \mathrm{K}(18-\mathrm{C}-6)\left[\mathrm{P}(\mathrm{CN})_{2}\right]
$$

(c) This work:

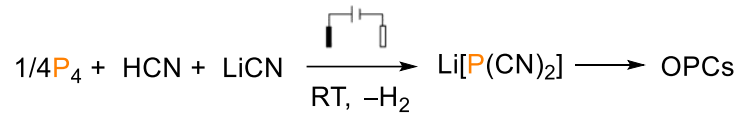

$$
\begin{aligned}
& \text { Ambient conditions; High yield; Atom economy; Undivided cell }
\end{aligned}
$$

Figure 1. (a) Selected examples of phosphorus transfer reagents. (b) Known methods to generate $\left[\mathrm{P}(\mathrm{CN})_{2}\right]^{-}$. (c) Electrochemical synthesis of $\left[\mathrm{P}(\mathrm{CN})_{2}\right]^{-}$from $\mathrm{P}_{4}$.

The isolation of the dicyanophosphide anion salt $\mathrm{Na}(18-\mathrm{C}$ 6) $\left[\mathrm{P}(\mathrm{CN})_{2}\right](18-\mathrm{C}-6=18$-crown-6) dates back to 1977 by the group of Schmidpeter but its chemistry has been scarcely investigated likely due to the lack of efficient synthetic routes for large scale syntheses. ${ }^{11}$ The known procedures include the reduction of $\mathrm{P}(\mathrm{CN})_{3}$ with $\mathrm{NaPO}(\mathrm{OEt})_{2},{ }^{11 a}$ the ligand exchange of [dppeP][BPh 4$]$ (dppe $=$ bis(diphenylphosphino)ethane) with cyanides and the disproportionation of $\mathrm{P}_{4}$ with $\mathrm{K}(18-\mathrm{C}-6) \mathrm{CN} .{ }^{12}$ These are typically associated with low efficiency and poor atom economy (Figure 1b). A handful of reports described the displacement of the cyano groups of $\left[\mathrm{P}(\mathrm{CN})_{2}\right]^{-}$by carbon- or/and phosphorus-based anionic nucleophiles and the halide substitution of 2-chloro imidazolium salts and alkyl iodides. ${ }^{13}$ 
We herein present the unprecedented chemoselective facile synthesis of $\left[\mathrm{P}(\mathrm{CN})_{2}\right]^{-}$via electrochemical activation of $\mathrm{P}_{4}$ at room temperature using hydrogen cyanide $(\mathrm{HCN})$ as the oxidant in an undivided cell (Figure 1c). The electronic structure of $\left[\mathrm{P}(\mathrm{CN})_{2}\right]^{-}$is examined by DFT calculations. The utility of $\left[\mathrm{P}(\mathrm{CN})_{2}\right]^{-}$towards neutral and anionic carbon-based nucleophiles selectively affords scarcely accessible OPCs, such as cyano-phosphinidenes, cyclophosphanes and phospholides. These pave a straightforward path for facile bridging of OPCs from $\mathrm{P}_{4}$.

The nucleophilic disproportionation of $\mathrm{P}_{4}$ by $\mathrm{K}(18-\mathrm{C}-6) \mathrm{CN}$ in boiling $\mathrm{MeCN}$ can generate $\mathrm{K}(18-\mathrm{C}-6)\left[\mathrm{P}(\mathrm{CN})_{2}\right]$ but at the cost of losing 15 equivalents of phosphorus (Figure 1b). ${ }^{12 \mathrm{~b}}$ We hypothesized that the controlled oxidation of $\mathrm{P}_{4}$ in the presence of cyanides might selectively afford $\left[\mathrm{P}(\mathrm{CN})_{2}\right]^{-}$. Specifically, electrochemical methods may be able to delicately control the oxidation from $\mathrm{P}(0)$ to $\mathrm{P}(+1)$ with the proper voltage. Hydrogen cyanide $(\mathrm{HCN})$, which is industrially produced, was postulated to work as the electrochemical oxidant and a cyanide source. However, to avoid the direct handling of $\mathrm{HCN}$ gas the combination of $\mathrm{Me}_{3} \mathrm{SiCN}$ with $\mathrm{LiOH}$ as a $\mathrm{HCN}$ surrogate was employed. This reaction also generated $\mathrm{LiCN}$ and $\left(\mathrm{Me}_{3} \mathrm{Si}\right)_{2} \mathrm{O}$ (Figure S1) and the former provides another equivalent of cyanide needed for the subsequent electrolysis.

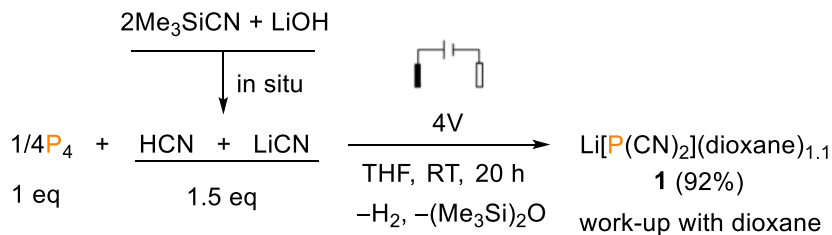

Figure 2. Electro-oxidation of $\mathrm{P}_{4}$ to $\mathrm{LiP}(\mathrm{CN})_{2}$.

An undivided cell at room temperature was equipped with graphite and platinum electrodes as the respective anode and cathode, then a THF solution of $\mathrm{P}_{4}, \mathrm{Me}_{3} \mathrm{SiCN}$ and $\mathrm{LiOH}$ was subjected to electrolysis at $4 \mathrm{~V}$ voltage (Figure 2 ). ${ }^{31} \mathrm{P}$ NMR analysis of the aliquots of the reaction mixture indicated the selective conversion of $\mathrm{P}_{4}$ to $\left[\mathrm{P}(\mathrm{CN})_{2}\right]^{-}(-196.7 \mathrm{ppm})$ and no other phosphorus-containing products or intermediates were observed. The electrolysis was complete within $20 \mathrm{~h}$ and subsequent workup with dioxane gave $\mathrm{Li}(\text { dioxane })_{1.1}\left[\mathrm{P}(\mathrm{CN})_{2}\right](\mathbf{1})$ as an analytically pure product in $92 \%$ yield. It is important to note that the reaction can be scaled up to make grams of $\mathrm{LiP}(\mathrm{CN})_{2}$.

No conversion was observed after stirring the same mixture for $10 \mathrm{~h}$ without electrolysis. In the presence of $50 \% \mathrm{~mol} \mathrm{LiCN}$, complete conversion of $\mathrm{P}_{4}$ took a shorter time (10h) and gave a similar yield. Mechanistically, $\mathrm{P}_{4}$ is oxidized to form $\left[\mathrm{P}(\mathrm{CN})_{2}\right]^{-}$on the anode and $\mathrm{HCN}$ is reduced to dihydrogen on the cathode. Gas bubbles was observed from the Pt electrode during the electrolysis. An analogous reaction using $\mathrm{MeCN}$ as solvent gave the same product and the formation of hydrogen was observed by ${ }^{1} \mathrm{H}$ NMR spectroscopy (Figure S2). A similar redox reaction occurred via the combination of $\mathrm{P}_{4}$ with $\mathrm{Me}_{3} \mathrm{SiCN}$ under the same conditions and the byproduct $\left(\mathrm{Me}_{3} \mathrm{Si}\right)_{2}$ was observed by ${ }^{1} \mathrm{H}$ NMR spectroscopy. While we were able to observe the generation of $\mathrm{M}\left[\mathrm{P}(\mathrm{CN})_{2}\right](\mathrm{M}=\mathrm{K}$, Na) using $\mathrm{KOH}$ or $\mathrm{NaOH}$, instead of $\mathrm{LiOH}$, the lack of appropriate electrolytes to maintain the conductivity obscures the isolation of analytically pure $\mathrm{M}\left[\mathrm{P}(\mathrm{CN})_{2}\right]$.

Alternatively, $\mathrm{M}\left[\mathrm{P}(\mathrm{CN})_{2}\right](\mathrm{M}=\mathrm{Li}, \mathrm{Na}, \mathrm{K})$ can be obtained by reduction of $\mathrm{P}(\mathrm{CN})_{3}$ with the corresponding alkali metals (See SI for details). Stirring a mixture of $\mathrm{P}(\mathrm{CN})_{3}$ with $\mathrm{Li}, \mathrm{Na}$ or $\mathrm{K}$ in THF at room temperature followed by extraction using dioxane gave the corresponding salts $\mathrm{M}\left[\mathrm{P}(\mathrm{CN})_{2}\right](\text { dioxane })_{\mathrm{x}}(\mathrm{M}=\mathrm{Li}, \mathrm{x}=0.8 ; \mathrm{M}=\mathrm{Na}$, $\mathrm{x}=0.5 ; \mathrm{M}=\mathrm{K}, \mathrm{x}=0)$ in good yield $(65-90 \%)$. The combination of such salts with 18-crown-6 gave the ensuing $\mathrm{M}(18-\mathrm{C}-6)\left[\mathrm{P}(\mathrm{CN})_{2}\right]$ $(\mathrm{M}=\mathrm{Na}, \mathrm{K})$. All these salts can be stored in the solid state under inert atmosphere over a week without noticeable decomposition.

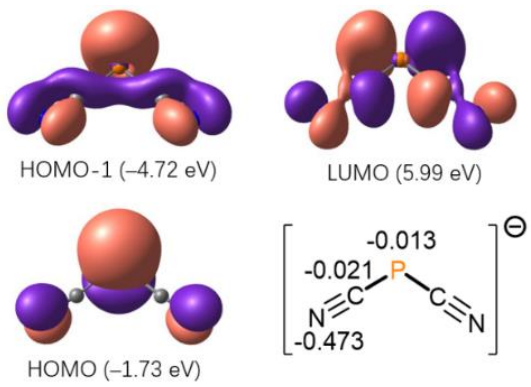

Figure 3. Frontier orbitals and NPA charge distribution of $\left[\mathrm{P}(\mathrm{CN})_{2}\right]^{-}$.

The electronic structure of the $\left[\mathrm{P}(\mathrm{CN})_{2}\right]^{-}$anion was probed by density functional theory (DFT) calculations (M06-2X/def2TZVP//M06-2X/def2-SVP) (Figure 3). The HOMO-1 (-4.72 eV) and HOMO $(-1.73 \mathrm{eV})$ are predominantly the in-plane and out-ofplane $\mathrm{P}$ lone pairs, respectively, while the LUMO exhibits features of $\pi^{*}$ orbitals over the anion with the major contribution of $\mathrm{P}$. The natural population analysis (NPA) reveals that the anionic charges are considerably located at two $\mathrm{N}$ atoms $(-0.47$ a.u. $)$ whereas the $\mathrm{P}$ atom bears almost no net charge ( -0.01 a.u.). The Wiberg bond indices (WBIs) of $\mathrm{P}-\mathrm{C}$ and $\mathrm{C}-\mathrm{N}$ bonds are 1.1 and 2.8 , respectively. Collectively, these results demonstrate the ambiphilic nature of $\mathrm{P}$.

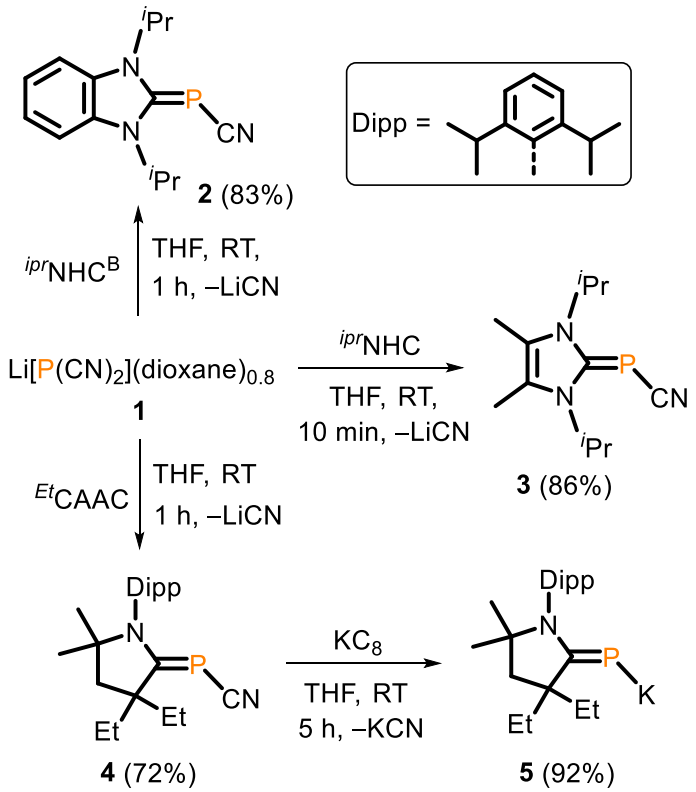

Figure 4. Reaction of $\left[\mathrm{P}(\mathrm{CN})_{2}\right]^{-}$with $\mathrm{NHC} / \mathrm{CAAC}$ and the reduction of 4 .

We then investigated the synthetic potential of $\left[\mathrm{P}(\mathrm{CN})_{2}\right]^{-}$for OPCs using carbon-based nucleophiles. Albeit the $\left[\mathrm{P}(\mathrm{CN})_{2}\right]^{-}$has an overall anionic nature, treatment of 1 with various neutral carbon nucleophiles (i.e. N-heterocyclic carbene (NHC) and cyclic(alkyl)(amino)carbene (CAAC)) gave rise to base-stabilized phosphinidenes 2-4, concurrent with the elimination of $\mathrm{LiCN}$. The ${ }^{31} \mathrm{P}$ NMR spectra of $\mathbf{2}, \mathbf{3}$ and $\mathbf{4}$ consist of a singlet at $-133.7,-154.0$ and $-59.6 \mathrm{ppm}$, respectively. Further confirmation of structures of 2-4 was carried out with single crystal X-ray diffraction (Figures $5 \mathrm{a}$ and S5,6), which reveals that the $\mathrm{C}(1)-\mathrm{P}(1)$ bond length in 4 $(1.748(2) \AA)$ is significantly shorter than those of $2(1.805(2) \AA)$ 
and 3 (1.821(3) $\AA$ ). These are consistent with the enhanced $\pi$-accepting ability of CAACs compared to NHCs. ${ }^{14}$ The formation of 2-4 indicates the facile replacement of $\mathrm{LiCN}$ with nucleophilic carbenes, reminiscent of examples of ligand exchange reactions at a phosphinidene described by Bertrand et al. ${ }^{15}$ Notably, while the chemistry of base-stabilized phosphinidenes is quite rich, their syntheses usually require multiple steps and relatively harsh conditions. ${ }^{16}$ Our synthetic route represents a two-step procedure accessing rare examples of cyano-substituted phosphinidenes from white phosphorus.

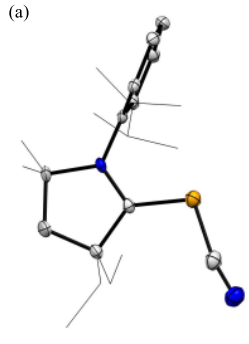

(c)

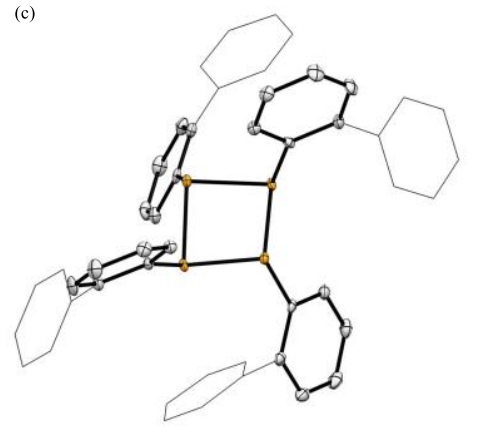

(b)
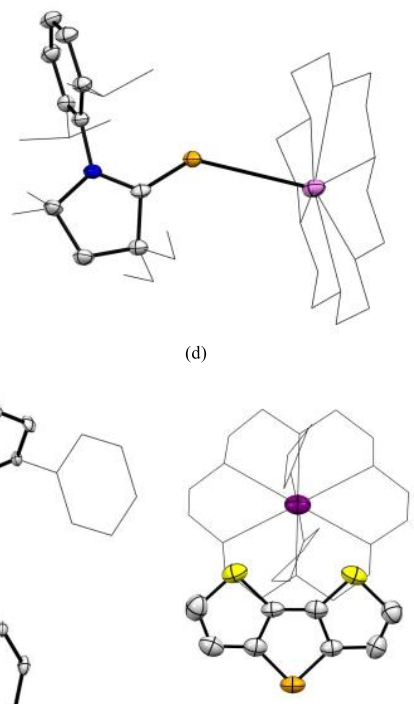

Figure 5. Solid-state structures of 4 (a), 5 (b), 9 (c) and 12 (d). C: grey; N: blue; P: orange; S: yellow; K: violet; Na: purple. Hydrogen atoms are omitted for clarity. Thermal ellipsoids are set at the $40 \%$ probability level.

In addition, reduction of $\mathbf{4}$ with excess $\mathrm{KC}_{8}$ at ambient temperature in THF for $5 \mathrm{~h}$ afforded species $\mathbf{5}$, which was after workup isolated as an orange solid in $92 \%$ yield. The ${ }^{31} \mathrm{P}$ NMR resonance of 5 (203.9 ppm) is comparable to those observed for $\left[{ }^{\mathrm{Me}} \mathrm{CAAC}=\mathrm{PLi}\right]_{2}(179.3 \mathrm{ppm}){ }^{17}$ and $\left[{ }^{\mathrm{Cy}} \mathrm{CAAC}=\mathrm{PK}\right]_{2}(206.9 \mathrm{ppm}) .{ }^{18}$ $\mathrm{X}$-ray quality single crystals of $\mathbf{5}(18-\mathrm{C}-6)$ were obtained via addition of $18-\mathrm{C}-6$ to a toluene solution of 5 (Figure $5 \mathrm{~b}$ ). In contrast to the dimeric structures of $\left[{ }^{\mathrm{Me}} \mathrm{CAAC}=\mathrm{PLi}\right]_{2}$ and $\left[{ }^{\mathrm{c}} \mathrm{CAAC}=\mathrm{PK}\right]_{2}$, 5(18-C-6) represents a rare example of a monomeric carbene-stabilized $\mathrm{P}^{-}$anion. The conversion of $\left[\mathrm{P}(\mathrm{CN})_{2}\right]^{-}$to $\left[{ }^{\mathrm{Et}} \mathrm{CAAC}=\mathrm{P}\right]^{-}$can be viewed as a formal " $\mathrm{P}$ " " anion delivery to carbenes, and thus showcases huge potential of $\left[\mathrm{P}(\mathrm{CN})_{2}\right]^{-}$for $\mathrm{P}$ atom transfer reactions. However, the formation of $\mathbf{5}$ is unique as the analogous reaction of $\mathbf{2}$ or $\mathbf{3}$ with $\mathrm{KC}_{8}$ is apparently inert.

Next, attempts to efficiently synthesize cyclophosphanes were undertaken (Figure 6). These species with a small $P_{n}(n=2-5)$ ring are usually prepared via reduction reactions of mono-substituted phosphorus dichlorides with undesirable reagents (e.g. alkalineearth reductants), which typically suffer from low chemoselectivity and operational complexity for purification. ${ }^{19}$ Dropwise addition of ${ }^{t} \mathrm{BuLi}$ to a THF solution of $\mathrm{Li}\left[\mathrm{P}(\mathrm{CN})_{2}\right] \cdot(\text { dioxane })_{\mathrm{x}}$ at $-35^{\circ} \mathrm{C}$ forms an intermediate $6\left({ }^{31} \mathrm{P}\right.$ NMR: $\left.-89.9 \mathrm{ppm}\right)$ that upon warming up to room temperature smoothly converted into two products $\left({ }^{t} \mathrm{BuP}\right)_{3} 7$ $\left({ }^{31} \mathrm{P}\right.$ NMR: -70.5 and $\left.-109.5 \mathrm{ppm}\right)$ and $\left({ }^{t} \mathrm{BuP}\right){ }_{4} 8\left({ }^{31} \mathrm{P} \mathrm{NMR}:-57.1\right.$ ppm) in a molar ratio of $1: 1 .^{20}$ Heating the reaction mixture at 70 ${ }^{\circ} \mathrm{C}$ for $24 \mathrm{~h}$ resulted in complete conversion into $\mathbf{8}$. As early work by Schmidpeter and co-workers described the reaction of $\mathrm{K}\left[\mathrm{P}(\mathrm{CN})_{2}\right]$ with $\mathrm{PhLi}$ leading to an equilibrium of $\mathrm{M}[\mathrm{PhPCN}](\mathrm{M}=\mathrm{Li}$ or $\mathrm{K})$ and the pentaphenyl pentaphospholane $(\mathrm{PhP})_{5},{ }^{13 \mathrm{c}}$ the cyanide anion in the reaction mixture is proposed to promote the transformation of 7 to 8 . Indeed, in the absence of cyanide the thermal rearrangement of 7 to 8 requires much higher temperature (i.e. $200^{\circ} \mathrm{C}$ ). ${ }^{21} \mathrm{In}$ a similar vein, we reacted $\operatorname{ArLi}\left(\mathrm{Ar}=1,1^{\prime}\right.$-biphenyl-2-yl) with $\mathbf{1}$ at room temperature to give (ArP) 49 in $76 \%$ yield (Figures $5 \mathrm{c}$ and $6 \mathrm{~b}$ ). In this case, no cyclotriphosphane $(\mathrm{ArP})_{3}$ was observed.

(a)

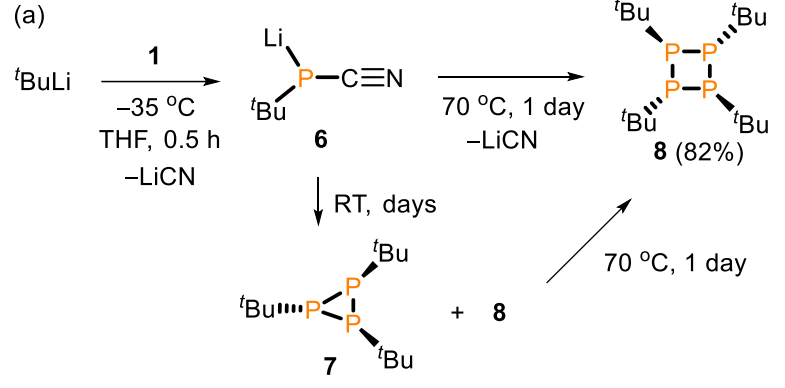

(b)

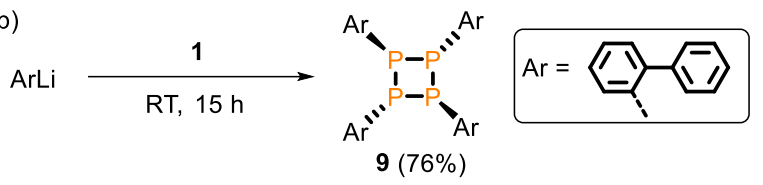

Figure 6. Reaction of organolithium reagents with $\left[\mathrm{P}(\mathrm{CN})_{2}\right]^{-}$.

Phospholides featuring an anionic unsaturated five-membered $\mathrm{P}_{1} \mathrm{C}_{4}$ ring have received tremendous interest in the past decades due to the fundamental significance of the structural and electronic properties as well as their applications in synthetic chemistry. ${ }^{22} \mathrm{We}$ envisioned the likelihood that the simple reaction of $\left[\mathrm{P}(\mathrm{CN})_{2}\right]^{-}$with organo-dilithium reagents would furnish phospholides, which are versatile precursors for synthesis of phosphole-based materials. ${ }^{23}$ Gratifyingly, addition of $\mathrm{Na}(18-\mathrm{C}-6)\left[\mathrm{P}(\mathrm{CN})_{2}\right]$ or 1 to the respective dilithium reagents gave rise to the corresponding phospholides 10$\mathbf{1 2}$ as a single P-containing product (Figure 7). 10-12 were isolated in moderate to good yield (62\%-84\%) and their structures were further authenticated by X-ray diffraction (Figures $5 \mathrm{~d}$ and S7-8). Although the generation and synthetic applications of phospholides $10,{ }^{24} \mathbf{1 1}^{25}$ as well as the studies of derivatives of $\mathbf{1 2}^{26}$ as luminescent materials have been reported, the solid-state structures of these anions are hitherto unknown. The synthetic method presented herein provides access to phospholides from $\mathrm{P}_{4}$ in a two-step fashion via $\left[\mathrm{P}(\mathrm{CN})_{2}\right]^{-}$as a bridge. It is important to note that the current protocols for phospholides generation require multistep synthesis, involving the use of phosphorus trihalides. ${ }^{27}$ Zhang et. al. reported the direct facile synthesis of phospholides from $\mathrm{P}_{4}$ but with low $\mathrm{P}$ atom economy (theoretically loss of $75 \% \mathrm{P}$ atoms). ${ }^{5 \mathrm{~g}, 5 \mathrm{l}, 28}$
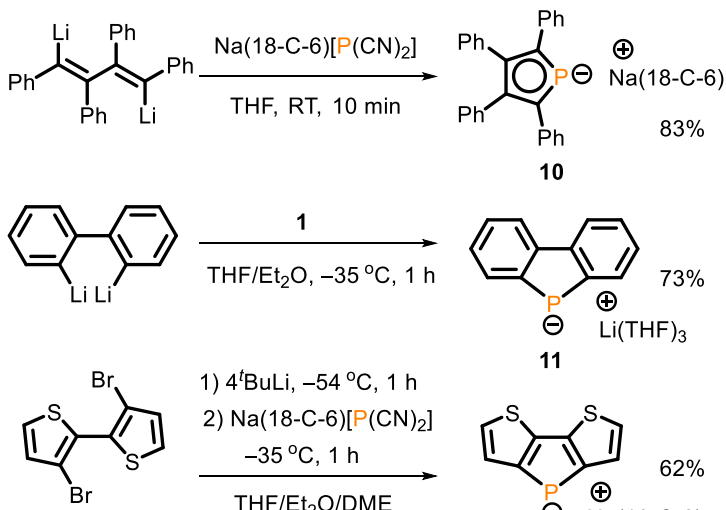

1) $4^{t} \mathrm{BuLi},-54^{\circ} \mathrm{C}, 1 \mathrm{~h}$

2) $\mathrm{Na}(18-\mathrm{C}-6)\left[\mathrm{P}(\mathrm{CN})_{2}\right]$
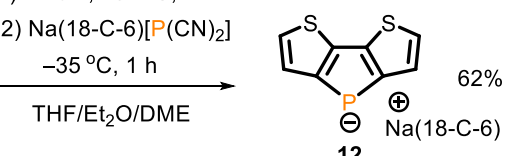
Figure 7. Synthesis of phospholides from $\left[\mathrm{P}(\mathrm{CN})_{2}\right]^{-}$.

To conclude, we have showcased a practical versatile approach for the conversion of $\mathrm{P}_{4}$ into useful OPCs with high $\mathrm{P}$ atom economy via $\left[\mathrm{P}(\mathrm{CN})_{2}\right]^{-}$, exemplified by the effective synthesis of basestabilized cyano-phosphinidenes $\mathbf{2 - 4}$, cyclophosphanes 7-9, and phospholides 10-12. Importantly, this anion is readily available from an unprecedented electrochemical activation of $\mathrm{P}_{4}$ on a gram scale. The practical simplicity of our strategy may spur considerable interest in development of $\left[\mathrm{P}(\mathrm{CN})_{2}\right]^{-}$that has been relatively dormant for many years. The utility of this approach directly from $\mathrm{P}_{4}$ to construct other useful OPCs as well as unusual inorganic/organic phosphorus skeletons are the subject of ongoing work.

\section{AUTHOR INFORMATION}

\section{Corresponding Author}

Liu Leo Liu

E-mail: liuleoliu@sustech.edu.cn

\section{Notes}

The authors declare no competing financial interests.

\section{ACKNOWLEDGMENT}

We gratefully acknowledge financial support from the National Natural Science Foundation of China (22101114) and SUSTech startup fund (Y01216248). The theoretical work is supported by the Center for Computational Science and Engineering and CHEM High-Performance Supercomputer Cluster located in the Department of Chemistry at SUSTech. We thank Drs. Xiaoyong Chang, Yuhui Hua, Zhe Huang and Rui Wei at SUSTech for helpful discussions and assistance in X-ray diffraction analyses. Prof. Chuan $\mathrm{He}$ and Dr. Jie Ke are thanked for assistance in electrolysis experiments. We thank Profs. Yufen Zhao and Guo Tang for providing $\mathrm{P}_{4}$. We thank Dr. D. A. Ruiz for valuable discussion.

\section{REFERENCES}

1. (a) De Boer, M. A.; Wolzak, L.; Slootweg, J. C., Phosphorus: reserves, production, and applications. In Phosphorus Recovery and Recycling, Springer: 2019; pp 75-100; (b) Corbridge, D. E., Phosphorus: chemistry, biochemistry and technology, 6th ed.;. CRC press: 2016; (c) Dietliker, K.; Jung, T.; Benkhoff, J.; Kura, H.; Matsumoto, A.; Oka, H.; Hristova, D.; Gescheidt, G.; Rist, G., New Developments in Photoinitiators. Macromol. Symp. 2004, 217, 77-98.

2. (a) Bettermann, G.; Krause, W.; Riess, G.; Hofmann, T., Phosphorus compounds, inorganic. Ullmann's Encyclopedia of Industrial Chemistry 2000; (b) Geeson, M. B.; Cummins, C. C., Let's Make White Phosphorus Obsolete. ACS Cent. Sci. 2020, 6, 848-860.

3. Weferling, N.; Zhang, S. M.; Chiang, C. H., Commercial organophosphorus chemicals: status and new developments. Procedia Engineering 2016, 138, 291-301.

4. (a) Cossairt, B. M.; Cummins, C. C., Radical synthesis of trialkyl, triaryl, trisilyl and tristannyl phosphines from P4. New J. Chem. 2010, 34, 1533-1536; (b) Cossairt, B. M.; Piro, N. A.; Cummins, C. C., Early-transition-metal-mediated activation and transformation of white phosphorus. Chem. Rev. 2010, 110, 41644177; (c) Caporali, M.; Gonsalvi, L.; Rossin, A.; Peruzzini, M., P4 activation by late-transition metal complexes. Chem. Rev. 2010, 110, 4178-4235; (d) Scheer, M.; Balazs, G.; Seitz, A., P4 activation by main group elements and compounds. Chem. Rev. 2010, 110, 4236-4256; (e) Martin, D.; Soleilhavoup, M.; Bertrand, G., Stable singlet carbenes as mimics for transition metal centers. Chem. Sci.
2011, 2, 389-399; (f) Giffin, N. A.; Masuda, J. D., Reactivity of white phosphorus with compounds of the p-block. Coord. Chem. Rev. 2011, 255, 1342-1359; (g) Khan, S.; Sen, S. S.; Roesky, H. W., Activation of phosphorus by group 14 elements in low oxidation states. Chem. Commun. 2012, 48, 2169-2179; (h) Holthausen, M. H.; Weigand, J. J., The chemistry of cationic polyphosphorus cages-syntheses, structure and reactivity. Chem. Soc. Rev. 2014, 43, 6639-6657; (i) Borger, J. E.; Ehlers, A. W.; Slootweg, J. C.; Lammertsma, K., Functionalization of P4 through Direct P-C Bond Formation. Chem. Eur. J. 2017, 23, 11738-11746; (j) Huangfu, X.; Zhang, Y.; Chen, P.; Lu, G.; Cao, Y.; Tang, G.; Zhao, Y., Synthesis of mixed phosphorotrithioates from white phosphorus. Green Chem. 2020, 22, 8353-8359; (k) Giusti, L.; Landaeta, V. R.; Vanni, M.; Kelly, J. A.; Wolf, R.; Caporali, M., Coordination chemistry of elemental phosphorus. Coord. Chem. Rev. 2021, 441, 213927.

5. (a) Masuda, J. D.; Schoeller, W. W.; Donnadieu, B.; Bertrand, G., Carbene Activation of P4 and Subsequent Derivatization. Angew. Chem., Int. Ed. 2007, 46, 7052-7055; (b) Masuda, J. D.; Schoeller, W. W.; Donnadieu, B.; Bertrand, G., NHC-Mediated Aggregation of P4: Isolation of a P12 Cluster. J. Am. Chem. Soc. 2007, 129, 14180-14181; (c) Tofan, D.; Cummins, C. C., Photochemical Incorporation of Diphosphorus Units into Organic Molecules. Angew. Chem., Int. Ed. 2010, 49, 7516-7518; (d) Dorsey, C. L.; Squires, B. M.; Hudnall, T. W., Isolation of a Neutral P8 Cluster by [2+2] Cycloaddition of a Diphosphene Facilitated by Carbene Activation of White Phosphorus. Angew. Chem., Int. Ed. 2013, 52, 4462-4465; (e) Heinl, S.; Reisinger, S.; Schwarzmaier, C.; Bodensteiner, M.; Scheer, M., Selective Functionalization of $\mathrm{P} 4$ by Metal-Mediated C-P Bond Formation. Angew. Chem., Int. Ed. 2014, 53, 7639-7642; (f) Borger, J. E.; Ehlers, A. W.; Lutz, M.; Slootweg, J. C.; Lammertsma, K., Functionalization of P4 Using a Lewis Acid Stabilized Bicyclo[1.1.0]tetraphosphabutane Anion. Angew. Chem., Int. Ed. 2014, 53, 12836-12839; (g) Xu, L.; Chi, Y.; Du, S.; Zhang, W. $\mathrm{X}$; Xi, Z., Direct synthesis of phospholyl lithium from white phosphorus. Angew. Chem., Int. Ed. 2016, 55, 9187-9190; (h) Du, S.; Yin, J.; Chi, Y.; Xu, L.; Zhang, W. X., Dual Functionalization of White Phosphorus: Formation, Characterization, and Reactivity of Rare - Earth - Metal Cyclo - P3 Complexes. Angew. Chem., Int. Ed. 2017, 56, 15886-15890; (i) Borger, J. E.; Ehlers, A. W.; Lutz, M.; Slootweg, J. C.; Lammertsma, K., Selective [3+1] Fragmentations of P4 by "P" Transfer from a Lewis Acid Stabilized [RP4]-Butterfly Anion. Angew. Chem., Int. Ed. 2017, 56, 285-290; (j) Seitz, A. E.; Hippauf, F.; Kremer, W.; Kaskel, S.; Scheer, M., Facile storage and release of white phosphorus and yellow arsenic. Nat. Commun. 2018, 9, 361; (k) Du, S.; Yang, J.; Hu, J.; Chai, Z.; Luo, G.; Luo, Y.; Zhang, W.-X.; Xi, Z., Direct Functionalization of White Phosphorus to Cyclotetraphosphanes: Selective Formation of Four P-C Bonds. J. Am. Chem. Soc. 2019, 141, 68436847; (1) Du, S.; Hu, J.; Chai, Z.; Zhang, W.-X.; Xi, Z., Isolation and Characterization of Four Phosphorus Cluster Anions P73-, P144-, P162- and P264- from the Nucleophilic Functionalization of White Phosphorus with 1,4-Dilithio-1,3-butadienes. Chin. J. Chem. 2019, 37, 71-75; (m) Zhang, F.; Zhang, J.; Chen, Z.; Weng, L.; Zhou, X., An Yttrium Organic cyclo-P4 Complex and Its Selective Conversions. Inorg. Chem. 2019, 58, 8451-8459; (n) Du, S.; Chai, Z.; Hu, J.; Zhang, W.-X.; Xi, Z., Isolation and Characterization of a Trinuclear Rare-Earth Metal Complex Containing a Bicyclo[3.1.0]-P<sub $>6</$ sub $><$ sup $>4-</$ sup $>$ Ligand. Chin. J. Org. Chem. 2019, 39, 2338-2342.

6. (a) Lennert, U.; Arockiam, P. B.; Streitferdt, V.; Scott, D. J.; Rödl, C.; Gschwind, R. M.; Wolf, R., Direct catalytic transformation of white phosphorus into arylphosphines and phosphonium salts. Nat. Catal. 2019, 2, 1101-1106; (b) Rothfelder, R.; Streitferdt, V.; Lennert, U.; Cammarata, J.; Scott, D. J.; Zeitler, K.; Gschwind, R. M.; Wolf, R., Photocatalytic Arylation 
of P4 and PH3: Reaction Development Through Mechanistic Insight. Angew. Chem., Int. Ed., 10.1002/anie.202110619.

7. (a) Geeson, M. B.; Cummins, C. C., Phosphoric acid as a precursor to chemicals traditionally synthesized from white phosphorus. Science 2018, 359, 1383-1385; (b) Geeson, M. B.; Ríos, P.; Transue, W. J.; Cummins, C. C., Orthophosphate and Sulfate Utilization for $\mathrm{C}-\mathrm{E}(\mathrm{E}=\mathrm{P}, \mathrm{S})$ Bond Formation via Trichlorosilyl Phosphide and Sulfide Anions. J. Am. Chem. Soc. 2019, 141, 6375-6384.

$8 . \quad$ (a) Goicoechea, J. M.; Grützmacher, H., The Chemistry of the 2-Phosphaethynolate Anion. Angew. Chem., Int. Ed. 2018, 57, 16968-16994; (b) Weber, L., 2-Phospha- and 2Arsaethynolates - Versatile Building Blocks in Modern Synthetic Chemistry. Eur. J. Inorg. Chem. 2018, 2018, 2175-2227.

9. Scott, D. J.; Cammarata, J.; Schimpf, M.; Wolf, R., Synthesis of monophosphines directly from white phosphorus. Nat. Chem. 2021, 13, 458-464.

10. (a) Kargin, Y. M.; Budnikova, Y. G., Electrochemistry of Organophosphorus Compounds. Russ. J. Gen. Chem. 2001, 71, 1393-1421; (b) Yakhvarov, D. G.; Gorbachuk, E. V.; Sinyashin, O. G., Electrode Reactions of Elemental (White) Phosphorus and Phosphane PH3. Eur. J. Inorg. Chem. 2013, 2013, 4709-4726; (c) Budnikova, Y. H.; Gryaznova, T. V.; Grinenko, V. V.; Dudkina, Y. B.; Khrizanforov, M. N., Eco-efficient electrocatalytic C-P bond formation. Pure Appl. Chem. 2017, 89, 311-330.

11. (a) Schmidpeter, A.; Zwaschka, F., Dicynophosphide. Angew. Chem. Int. Ed. Engl. 1977, 16, 704-705; (b) Sheldrick, W. S.; Kroner, J.; Zwaschka, F.; Schmidpeter, A., Structure of the Dicyanophosphide Ion in a Crown-Ether Sodium Salt. Angew. Chem. Int. Ed. Engl. 1979, 18, 934-935.

12. (a) Binder, J. F.; Kosnik, S. C.; St Onge, P. B. J.; Macdonald, C. L. B., Synthesis of Heavy Dicyanamide Homologues from Air-Stable Precursors. Chem. Eur. J. 2018, 24, 14644-14648; (b) Schmidpeter, A.; Burget, G.; Chandler, D. J.; Jones, R. A., ([18] Crown - 6) Potassium Dicyanophosphide (1 - ). Inorg. Synth. 1989, 25, 126-129; (c) Schmidpeter, A.; Burget, G.; Zwaschka, F.; Sheldrick, W. S., Cyanphosphorverbindungen. IX. Cyanidabbau von weißem Phosphor zu Dicyanphosphiden und die Dicyanphosphid-Struktur. Z. Anorg. Allg. Chem. 1985, 527, 17-32. 13. (a) Schmidpeter, A.; Gebler, W.; Zwaschka, F.; Sheldrick, W. S., The PCN Group as a Pseudochalcogen; Cyanophosphinidene - Substituted Heterocycles. Angew. Chem. Int. Ed. Engl. 1980, 19, 722-723; (b) Schmidpeter, A.; Bürget, G., Dicyanphosphid-Reaktionen [1]/Dicyanophosphide Reactions [1]. Z. Naturforsch. B 1985, 40, 1306-1313; (c) Schmidpeter, A.; Zirzow, K. H.; Burget, G.; Huttner, G.; Jibril, I., Cyanidabbau von (PhP) 5: Bildung, Struktur und Reaktionen des Phenyl cyanphosphid - Ions. Chem. Ber. 1984, 117, 1695-1706; (d) Hoge, B.; Panne, P., Synthesis of a Functional C2 - Symmetrical Bidentate Diphenylphosphonite DIOP Derivative and Its Conversion into the Corresponding $\pi$ - Acidic Bis (pentafluorophenyl) and Bis (p - tetrafluoropyridyl) Compounds. Chem. Eur. J. 2006, 12, 9025-9035.

14. Back, O.; Henry-Ellinger, M.; Martin, C. D.; Martin, D.; Bertrand, G., 31P NMR Chemical Shifts of CarbenePhosphinidene Adducts as an Indicator of the $\pi$-Accepting Properties of Carbenes. Angew. Chem., Int. Ed. 2013, 52, 29392943.

15. Hansmann, M. M.; Bertrand, G., Transition-Metal-like Behavior of Main Group Elements: Ligand Exchange at a Phosphinidene. J. Am. Chem. Soc. 2016, 138, 15885-15888.

16. (a) Schwedtmann, K.; Zanoni, G.; Weigand, J. J., Recent Advances in Imidazoliumyl-Substituted Phosphorus Compounds. Chem. Asian J. 2018, 13, 1388-1405; (b) Krachko, T.; Slootweg, J. C., N-Heterocyclic Carbene-Phosphinidene Adducts: Synthesis,
Properties, and Applications. Eur. J. Inorg. Chem. 2018, 2018, 2734-2754.

17. (a) Kundu, S.; Sinhababu, S.; Luebben, A. V.; Mondal, T.; Koley, D.; Dittrich, B.; Roesky, H. W., Reagent for Introducing Base-Stabilized Phosphorus Atoms into Organic and Inorganic Compounds. J. Am. Chem. Soc. 2018, 140, 151-154; (b) Kundu, S.; Sinhababu, S.; Siddiqui, M. M.; Luebben, A. V.; Dittrich, B.; Yang, T.; Frenking, G.; Roesky, H. W., Comparison of Two Phosphinidenes Binding to Silicon(IV)dichloride as well as to Silylene. J. Am. Chem. Soc. 2018, 140, 9409-9412.

18. Kulkarni, A.; Arumugam, S.; Francis, M.; Reddy, P. G.; Nag, E.; Gorantla, S. M. N. V. T.; Mondal, K. C.; Roy, S., Frontispiece: Solid-State Isolation of Cyclic Alkyl(Amino) Carbene (cAAC)-Supported Structurally Diverse Alkali MetalPhosphinidenides. Chem. Eur. J. 2021, 27.

19. Eilrich, V. J.; Hey-Hawkins, E., Cyclooligophosphanes and their coordination chemistry. Coord. Chem. Rev. 2021, 437, 213749.

20. Baudler, M.; Glinka, K.; Cowley, A. H.; Pakulski, M., Organocyclophosphanes. In Inorg. Synth., 1989; pp 1-5.

21. Baudler, M.; Hahn, J.; Clef, E., Contributions to the Chemistry of Phosphorus. 139. Triethylcyclotriphosphane, Trimethylcyclotriphosphane-equilibria Between Cyclophosphanes (PR)n at Elevated-Temperatures. Z. Naturforsch., B: Anorg. Chem., Org. Chem. 1984, 39, 438-444.

22. (a) Mathey, F., The chemistry of phospha-and polyphosphacyclopentadienide anions. Coord. Chem. Rev. 1994, 137, 1-52; (b) Mathey, F., Recent advances in the chemistry of phospholide and polyphospholide ions. J. Organomet. Chem. 1994, 475, 25-30; (c) Mathey, F., The organic chemistry of phospholes. Chem. Rev. 1988, 88, 429-453.

23. (a) Duffy, M. P.; Bouit, P. A.; Hissler, M., Applications of Phosphorus-Based Materials in Optoelectronics. John Wiley \& Sons Ltd.: Hoboken, Chichester: 2018; (b) Duffy, M. P.; Delaunay, W.; Bouit, P.-A.; Hissler, M., $\pi$-Conjugated phospholes and their incorporation into devices: components with a great deal of potential. Chem. Soc. Rev. 2016, 45, 5296-5310; (c) Baumgartner, T., Insights on the design and electron-acceptor properties of conjugated organophosphorus materials. Acc. Chem. Res. 2014, 47, 1613-1622; (d) Romero-Nieto, C.; Baumgartner, T., Dithieno [3, 2b: 2' , 3' -d] phospholes: A Look Back at the First Decade. Synlett 2013, 24, 920-937; (e) Ren, Y.; Baumgartner, T., Combining form with function - the dawn of phosphole-based functional materials. Dalton Trans. 2012, 41, 7792-7800.

24. (a) Román, E.; Leiva, A. M.; Casasempere, M. A.; Charrier, C.; Mathey, F.; Garland, M. T.; Le Marouille, J.-Y., Nouvell préparation, propriétés electrochimiques et etude structurale des phosphaferrocenes $\eta 5$-C5Me5Fe- $\eta 5-\mathrm{PC} 4$ (R4). $J$. Organomet. Chem. 1986, 309, 323-332; (b) Thomson, C.; Kilcast, D., Novel Radicals from the Reaction of Phospholes with Potassium. Angew. Chem. Int. Ed. Engl. 1970, 9, 310-311.

25. Krauss, I. J.; Wang, C. C.-Y.; Leighton, J. L., Highly regioselective and diastereoselective directed hydroformylation of allylic ethers: a new approach to propionate aldol synthesis. J. Am. Chem. Soc. 2001, 123, 11514-11515.

26. (a) Asok, N.; Gaffen, J. R.; Pradhan, E.; Zeng, T.; Baumgartner, T., Structure-reactivity studies on hypervalent square-pyramidal dithieno [3, 2-b: $2^{\prime}, 3^{\prime}$-d] phospholes. Dalton Trans. 2021, 50, 2243-2252; (b) Gaffen, J. R.; Bentley, J. N.; Torres, L. C.; Chu, C.; Baumgartner, T.; Caputo, C. B., A simple and effective method of determining Lewis acidity by using fluorescence. Chem 2019, 5, 1567-1583.

27. (a) Xu, Y.; Wang, Z.; Gan, Z.; Xi, Q.; Duan, Z.; Mathey, F., Versatile synthesis of phospholides from open-chain precursors. Application to annelated pyrrole-and silole-phosphole rings. $\mathrm{Org}$. Lett. 2015, 17, 1732-1734; (b) Westerhausen, M.; Digeser, M. H.; 
Nöth, H.; Ponikwar, W.; Seifert, T.; Polborn, K., 2, 5-Diphenyl-3, 4-bis (trimethylsilyl)-1-phosphacyclopentadienide as a Ligand at Calcium, Strontium, and Tin (II). Inorg. Chem. 1999, 38, $3207-$ 3214; (c) Gudat, D.; Bajorat, V.; Häp, S.; Nieger, M.; Schröder, G., Reduction of Bis (phosphonio) isophosphindolides to Phosphane - Functionalized Benzo [c] phospholides. Eur. J. Inorg. Chem. 1999, 1999, 1169-1174; (d) Holand, S.; Jeanjean, M.; Mathey, F., A Straightforward Access to a - Functional Phospholide Ions. Angew. Chem. Int. Ed. Engl. 1997, 36, 98-100; (e) Niecke, E.; Nieger, M.; Wenderoth, P., Phosphindolyl Anions by Elimination from 1 - Phosphoallyllithium Complexes - $\eta 5$ and $\eta 3$ Coordination of a Phospholyl Fragment. Angew. Chem. Int. Ed. Engl. 1994, 33, 353-354; (f) Braye, E.; Caplier, I.; Saussez, R., Alkali aza-, phospha-and arsacyclopentadienides and their chemical properties. Tetrahedron 1971, 27, 5523-5537.

28. Luo, G.; Du, S.; Wang, P.; Liu, F.; Zhang, W.-X.; Luo, Y., Fragmentation Mechanism of White Phosphorus: A Theoretical Insight into Multiple Cleavage/Formation of $\mathrm{P}-\mathrm{P}$ and $\mathrm{P}-\mathrm{C}$ Bonds. Chem. Eur. J. 2020, 26, 13282-13287. 


\section{SYNOPSIS TOC.}

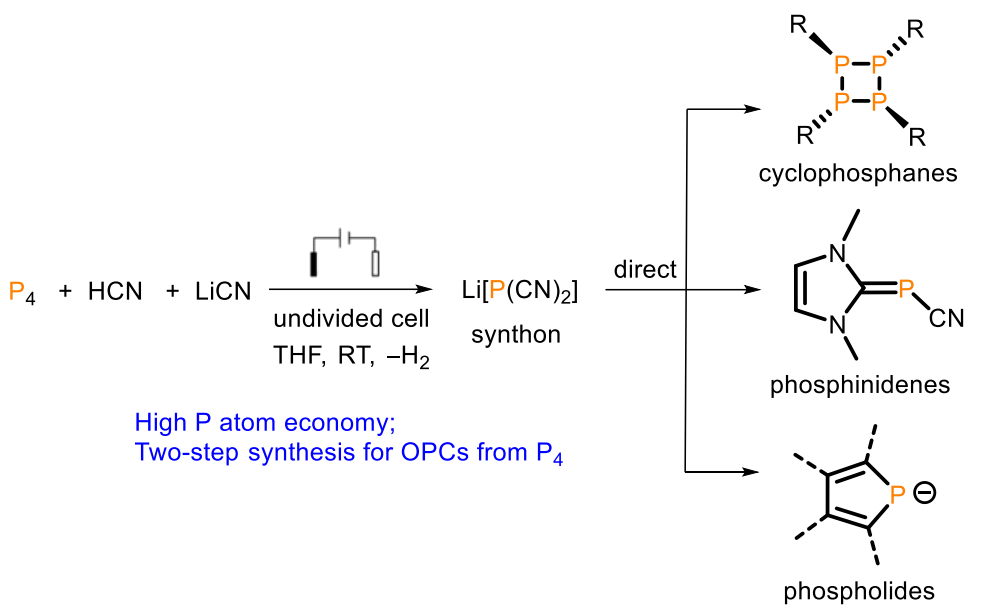

